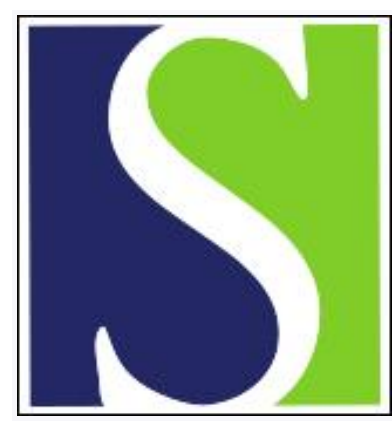

Scand J Work Environ Health 1992;18(5):298-301

https://doi.org/10.5271/sjweh.1573

Issue date: 01 Oct 1992

Fecundity and the use of video display terminals.

by Brandt LP, Nielsen CV

Affiliation: Institute of Epidemiology and Social Medicine, University of Aarhus, Denmark.

This article in PubMed: www.ncbi.nlm.nih.gov/pubmed/1439656 


\title{
Fecundity and the use of video display terminals
}

\author{
by Lars PA Brandt, MD, ${ }^{1}$ Claus V Nielsen, $M^{2}$
}

\begin{abstract}
BRANDT LPA, NIELSEN CV. Fecundity and the use of video display terminals. Scand J Work Environ Health 1992;18:298-301. The association between prolonged waiting time to pregnancy and the use of a video display terminal (VDT) was investigated among commercial and clerical employees in Denmark. Information on 24352 pregnancies was obtained through register linkage with two national registers. A random sample of 2252 pregnancies was drawn, and the women were asked for information on waiting time to pregnancy, occupational exposures, and life-style factors. The overall exposure to a VDT indicated a slightly increased association with prolonged waiting time to pregnancy. The relative risks for waiting more than one year were $1.23,0.77$, and 1.61 for the women who worked with a VDT for $1-10$, $11-20$, and $\geq 21 \mathrm{~h}$ per week, respectively. Only the last relative risk was statistically significant. The results could be explained by methodological shortcomings such as recall bias or confounding by alternative factors that might affect time to pregnancy, or simply by the lack of statistical power.
\end{abstract}

Key terms: parity, reproduction, smoking, time to pregnancy.

The possible effects of the use of a video display terminal (VDT) on reproduction have been investigated during the last decade with the main focus on spontaneous abortion and congenital malformations. No scientific evidence has been found to support the early case reports on clusters of spontaneous abortions and infants with congenital malformations among women working with a VDT $(1-10)$. Two of the studies $(4,6)$ reported, however, an increased risk of spontaneous abortion among women working more than $20 \mathrm{~h}$ per week with a VDT, but the authors explained their findings as a result of selection bias (6) or job stress (4).

Other aspects of reproduction, apart from spontaneous abortion and congenital malformations, may however be at risk. For instance, no research has been done on a possible association between the use of a VDT and reduced fecundity. Reduced fecundity indicates lack of conception or implantation or the early loss of pregnancy at any stage from gametogenesis to early unrecognized spontaneous abortion. The number of menstrual cycles (in the absence of any form of contraception) before a couple conceives (ie, time to pregnancy) can be used as an estimate of fecundity (the probability of becoming pregnant within a cycle), given regular unprotected sexual intercourse. Baird et al (11) have suggested the use of time to pregnancy as a screening tool for identifying factors that might interfere with the reproductive process. This paper

1 Institute of Epidemiology and Social Medicine, University of Aarhus, Aarhus, Denmark.

2 Department of Occupational Medicine, University Hospital of Aarhus, Aarhus, Denmark.

Reprint requests to: Dr LPA Brandt, Institute of Epidemiology and Social Medicine, University of Aarhus, Hoegh Guldbergsgade 8, DK-8000 Aarhus, Denmark. presents results on fecundity, measured as time to pregnancy, and the use of video display terminals among commercial and clerical female employees in Denmark.

\section{Subjects and methods}

The reproductive histories of 214108 female members of the Union of Commercial and Clerical Employees in Denmark were obtained for 1983-1985 by register linkage with the Medical Birth Register and the $\mathrm{Na}$ tional Register of In-patients. The women's personal identification number was used as the identification key. All of the women were between the ages of 15 and 44 years. A total of 24352 pregnancies was registered, from which a random sample of 2252 pregnancies was drawn $(9.2 \%)$. More-detailed information on data collection has been given previously $(1,2)$.

A questionnaire was sent in September 1987 requesting information on time to pregnancy, occupational status, job title, job stress, ergonomic factors, exposure to organic solvents, VDT use, life-style factors, and health status. The response rate was $75.5 \%$ $(\mathrm{N}=1700)$. A random sample of nonrespondents was drawn $(\mathrm{N}=196)$. These women were contacted by telephone and interviewed in accordance with the questionnaire.

The question relating to time to pregnancy in this study was "How long did it take you to become pregnant, that is, what was the interval between stopping contraceptive use and becoming pregnant?" The alternative responses were $0-6$ months, 7-12 months, 13-24 months, 2 years or more, do not remember."

Only gainfully employed women were included in the analysis $(\mathrm{N}=1365)$. The statistical analysis was based on Mantel Haenszel's stratified analysis, obtaining adjusted relative risks (12). Table 1 shows the 
potential confounders that were considered in the analysis. Information from the random sample of the nonrespondents was used to estimate the direction and magnitude of nonresponse bias from calculations of the selection odds ratios (13).

To study the potential for recall bias, another measure of work with a VDT was used, that is, occupational titles were used as a job-exposure matrix. The amount of VDT work within each job reported by women with a waiting time to pregnancy of less than seven months was used to divide the occupational titles into two groups, in which less than $5 \%$ or more than $60 \%$ of the women worked with a VDT. The relative risks for increased waiting time to pregnancy were then calculated by comparison among these two groups.

\section{Results}

There were statistically significant associations between prolonged time to pregnancy ( $\geq 7$ months) and smoking $>10$ cigarettes daily [relative risk (RR) 1.63], age 25-34 years ( $R R$ 1.61), age $\geq 35$ years ( $R R 3.93$ ), and one or more previous pregnancies (RR 0.55 ). The corresponding figures using prolonged time to pregnancy as 13 months or more were $1.75,1.99,7.35$, and 0.39 , all again statistically significant.

Table 2 shows that there was no difference in the distribution of time to pregnancy within the groups of working and nonworking women.

There was a statistically significant increased relative risk for prolonged waiting time to pregnancy $(\geq 13$ months) only in the subgroup with $\geq 21$ h of VDT use per week [RR $1.61,95 \%$ confidence interval $(95 \% \mathrm{CI})$ 1.09-2.38] (table 3). The association was similar when the analysis was performed only for nulliparas (RR $1.62,95 \%$ CI $1.04-2.53)$ or for women working $\geq 35$ h per week (RR $1.71,95 \%$ CI $1.15-2.57$ ) (table 4). When using the job-exposure matrix, we found no associations between VDT work and increased time to pregnancy (table 5).

\section{Discussion}

The distribution of time to pregnancy among the study population (table 2) was rather similar to findings in a recent Danish study among pharmacy assistants (06 months $78 \%, 7-11$ months $9 \%, \geq 12$ months $13 \%$ ) (14).

Information on exposure was not collected prior to the occurrence of the outcome (waiting time to pregnancy). The exposure information concerned early pregnancy, and therefore represents a proxy variable for the proper exposure time. The validity of the proxy variable depends on the stability of the women's jobs over a period of 6-12 months. It seems that exposure was rather stable over time in that $83 \%(\mathrm{~N}=58)$ of the women with two pregnancies in the study period had the same exposure during both pregnancies. Still, bias due to a misclassification of exposure could exist if the women who had an increased waiting time to pregnancy tended to stop work when they became pregnant. However, no such tendency was found among the $17 \%$ of the women who had had an altered exposure from the first to the second pregnancy.

Lack of response to the questionnaire might have resulted in nonresponse bias. We studied the poten-

Table 1. Potential confounders and effect modifiers used in the multiple logistic regression analysis.

\begin{tabular}{ll}
\hline Covariable & Classification \\
\hline Education & $1-9$ years, 10 years, $>10$ years \\
Maternal age & $<25$ years, $25-34$ years, $\geq 35$ years \\
Previous pregnancies & Yes/no \\
Previous deliveries & Yes/no \\
Previous spontaneous abortions & Yes/no \\
Job stress factors & Three-level job-stress index, based \\
& on 12 questions on job stressors \\
Ergonomic factors & Heavy lifting, yes/no \\
& Sitting more than $1 \mathrm{~h}$ at a time dur- \\
ing a workday, yes/no \\
Standing more than $1 \mathrm{~h}$ at a time dur- \\
ing a workday, yes/no \\
Exposed daily at work, yes/no \\
Organic solvent & $1-34 \mathrm{~h}, \geq 35 \mathrm{~h}$ \\
Hours of work per week & $0,1-10, \geq 11$ cigarettes a day during \\
Smoking & $\begin{array}{l}\text { the first trimester } \\
\text { More than five drinks per week on the }\end{array}$ \\
Alcohol & average during the first trimester, \\
& yes/no \\
Daily medicine consumption during \\
the first trimester, yes/no \\
Medicine
\end{tabular}

Table 2. Distribution of time to pregnancy among working and nonworking women organized in the Union of Commercial and Clerical Employees in Denmark in 1983-1985.

\begin{tabular}{|c|c|c|c|c|c|c|c|c|c|c|}
\hline \multirow{3}{*}{ Group } & \multicolumn{10}{|c|}{ Time to pregnancy } \\
\hline & \multicolumn{2}{|c|}{$0-6$ months } & \multicolumn{2}{|c|}{$7-12$ months } & \multicolumn{2}{|c|}{$\geq 13$ months } & \multicolumn{2}{|c|}{ Unknown } & \multicolumn{2}{|c|}{ Total } \\
\hline & $\mathrm{N}$ & $\% a$ & $\mathrm{~N}$ & $\% a$ & $\mathbf{N}$ & $\% a$ & $\mathbf{N}$ & $\%^{a}$ & $\mathbf{N}$ & $\%$ \\
\hline $\begin{array}{l}\text { Working women } \\
\text { Nonworking women }\end{array}$ & $\begin{array}{r}1012 \\
251\end{array}$ & $\begin{array}{l}74.1 \\
74.9\end{array}$ & $\begin{array}{r}128 \\
29\end{array}$ & $\begin{array}{l}9.4 \\
8.7\end{array}$ & $\begin{array}{r}188 \\
49\end{array}$ & $\begin{array}{l}13.8 \\
14.6\end{array}$ & $\begin{array}{r}37 \\
6\end{array}$ & $\begin{array}{l}2.7 \\
1.8\end{array}$ & $\begin{array}{r}1365 \\
335\end{array}$ & $\begin{array}{l}100 \\
100\end{array}$ \\
\hline Total & 1263 & 74.3 & 157 & 9.2 & 237 & 14.0 & 43 & 2.5 & 1700 & 100 \\
\hline
\end{tabular}

a Percentage of all. 
Table 3. Work with a video display terminal (VDT) and time to pregnancy - adjusted relative risk and $95 \%$ confidence intervals $(95 \% \mathrm{Cl}$ ) for prolonged waiting time to pregnancy ( $\geq 7$ months or $\geq 13$ months compared with $<7$ months).

\begin{tabular}{|c|c|c|c|c|c|c|c|c|c|}
\hline \multirow{3}{*}{ Work with VDT } & \multicolumn{5}{|c|}{ Time to pregnancy } & \multicolumn{4}{|c|}{ Time to pregnancy } \\
\hline & \multirow[b]{2}{*}{$\begin{array}{c}0-6 \\
\text { months }\end{array}$} & \multirow[b]{2}{*}{$\begin{array}{l}7-12 \\
\text { months }\end{array}$} & \multirow[b]{2}{*}{$\begin{array}{c}\geq 13 \\
\text { months }\end{array}$} & \multirow[b]{2}{*}{ Unknown } & \multirow[b]{2}{*}{ Total } & \multicolumn{2}{|c|}{$\geq 7$ months } & \multicolumn{2}{|c|}{$\geq 13$ months } \\
\hline & & & & & & $\begin{array}{c}\text { Rela- } \\
\text { tive } \\
\text { risk }\end{array}$ & $95 \% \mathrm{Cl}$ & $\begin{array}{c}\text { Rela- } \\
\text { tive } \\
\text { risk }\end{array}$ & $95 \% \mathrm{Cl}$ \\
\hline None & 650 & 85 & 114 & 60 & 909 & 1.00 & . & 1.00 & $\cdot$ \\
\hline Any hours/week & 315 & 43 & 74 & 24 & 456 & 1.15 & $0.95-1.40$ & 1.27 & $0.98-1.65$ \\
\hline$<11$ hours/week & 184 & 23 & 40 & 9 & 256 & 1.11 & $0.87-1.42$ & 1.23 & $0.89-1.71$ \\
\hline $11-20$ hours/week & 68 & 12 & 10 & 3 & 93 & 0.98 & $0.67-1.44$ & 0.77 & $0.42-1.39$ \\
\hline$\geq 21$ hours/week & 60 & 8 & 22 & 3 & 93 & 1.32 & $0.97-1.82$ & 1.61 & $1.09-2.38$ \\
\hline $\begin{array}{l}\text { No information } \\
\text { on hours/week }\end{array}$ & 3 & - & 2 & 9 & 14 & $\cdot$ & . & $\cdot$ & $\cdot$ \\
\hline Total & 965 & 128 & 188 & 84 & 1365 & - & . & - & . \\
\hline
\end{tabular}

a Adjusted for smoking, age, and previous deliveries.

Table 4. Work with a video display terminal (VDT) and time to pregnancy - adjusted relative risk and $95 \%$ confidence intervals $(95 \% \mathrm{Cl})$ for prolonged waiting time to pregnancy ( $\geq 7$ months or $\geq 13$ months compared with $<7$ months) among nulliparas and among women working $\geq 35 \mathrm{~h}$ per week.

\begin{tabular}{|c|c|c|c|c|c|c|c|c|}
\hline \multirow{3}{*}{ Work with VDT } & \multicolumn{4}{|c|}{ Nulliparas } & \multicolumn{4}{|c|}{ Women working $\geq 35$ hours per week } \\
\hline & \multicolumn{2}{|c|}{$\geq 7$ months } & \multicolumn{2}{|c|}{$\geq 13$ months } & \multicolumn{2}{|c|}{$\geq 7$ months } & \multicolumn{2}{|c|}{$\geq 13$ months } \\
\hline & $\begin{array}{c}\text { Relative } \\
\text { risk }^{a}\end{array}$ & $95 \% \mathrm{Cl}$ & $\begin{array}{c}\text { Relative } \\
\text { risk }^{\mathbf{a}}\end{array}$ & $95 \% \mathrm{Cl}$ & $\begin{array}{c}\text { Relative } \\
\text { risk }^{\mathrm{a}}\end{array}$ & $95 \% \mathrm{Cl}$ & $\begin{array}{c}\text { Relative } \\
\text { risk }^{\mathrm{a}}\end{array}$ & $95 \% \mathrm{Cl}$ \\
\hline $\begin{array}{l}\text { Any hours/week } \\
<11 \text { hours/week } \\
11-20 \text { hours/week } \\
\geq 21 \text { hours/week }\end{array}$ & $\begin{array}{l}1.14 \\
0.98 \\
0.97 \\
1.30\end{array}$ & $\begin{array}{l}0.88-1.49 \\
0.69-1.38 \\
0.58-1.62 \\
0.88-1.91\end{array}$ & $\begin{array}{l}1.17 \\
0.91 \\
0.55 \\
1.62\end{array}$ & $\begin{array}{l}0.78-1.66 \\
0.57-1.45 \\
0.21-1.41 \\
1.04-2.53\end{array}$ & $\begin{array}{l}1.13 \\
1.06 \\
1.11 \\
1.28\end{array}$ & $\begin{array}{l}0.91-1.42 \\
0.80-1.41 \\
0.74-1.66 \\
0.91-1.80\end{array}$ & $\begin{array}{l}1.27 \\
1.13 \\
0.86 \\
1.71\end{array}$ & $\begin{array}{l}0.93-1.70 \\
0.77-1.56 \\
0.44-1.68 \\
1.15-2.57\end{array}$ \\
\hline
\end{tabular}

adjusted for smoking, age, and $\geq 35$ hours per week, yes/no.

b Adjusted for smoking, age, and previous pregnancies.

Table 5. Work with a video display terminal (VDT), as measureo by a job-exposure matrix, and time to pregnancy - adjusted relative risk and $95 \%$ confidence intervals $(95 \% \mathrm{Cl})$ for prolonged waiting time to pregnancy ( $\geq 7$ months or $\geq 13$ months compared with $<7$ months).

\begin{tabular}{|c|c|c|c|c|}
\hline & \multicolumn{4}{|c|}{ Time to pregnancy } \\
\hline & \multicolumn{2}{|c|}{$\geq 7$ months } & \multicolumn{2}{|c|}{$\geq 13$ months } \\
\hline & $\begin{array}{l}\text { Rela- } \\
\text { tive } \\
\text { riska }\end{array}$ & $95 \% \mathrm{Cl}$ & $\begin{array}{c}\text { Rela- } \\
\text { tive } \\
\text { riska }\end{array}$ & $95 \% \mathrm{Cl}$ \\
\hline $\begin{array}{l}\text { Occupational groups with } \\
\text { less than } 5 \% \text { VDT work }\end{array}$ & 1.00 & . & 1.00 & . \\
\hline $\begin{array}{l}\text { Occupational groups with } \\
\text { more than } 60 \% \text { VDT work }\end{array}$ & 1.21 & $0.77-1.84$ & 1.02 & $0.74-1.41$ \\
\hline
\end{tabular}

adjusted for age and previous deliveries.

tial risk of selection bias by applying the distribution of VDT use in the random sample of nonresponders to the whole group of nonresponders. The selection probabilities for the exposed and unexposed women with a time to pregnancy of less than seven months and seven months or more were estimated, and the selection odds ratio was calculated to be 1.01 , which means no selection bias due to nonresponse.
Using time to pregnancy as a measure of subfecundity means that women who did not become pregnant were not included, and the association between exposure and sterility was not investigated.

Information was not sought on the use of contraception nor on the frequency and timing of intercourse. The presence of organic disorders causing a prolonged waiting time for pregnancy, such as salpingitis and anovulation, was not known. Confounding might have been caused by such disorders.

Another source of confounding might have been an "infertile worker effect" (ie, if women with reduced fertility tend to stay in jobs and women who have proved their fertility by giving birth to children do not). However, the distribution of waiting time to pregnancy was the same among the working and nonworking women (table 2). But a selection effect could have still been operating within the group of working women if nulliparous women tended to work longer hours per week than women who already had children. The former group would have had a higher probability of high exposure, which would lead to confounding due to an association between a nulliparous state and VDT exposure. However the results for the nulliparas and 
the women working $\geq 35 \mathrm{~h}$ per week (table 4 ) showed almost the same relative risks as all the working women together.

Smoking, number of previous pregnancies, and age have been found to be associated with prolonged time to pregnancy in other studies $(11,15-17)$. The present study found the same associations, a result suggesting a high reliability of the measure "time to pregnancy."

The present study only showed a statistically significant association between prolonged waiting time to pregnancy ( $\geq 13$ months) and self-reported high exposure to VDT use ( $\geq 21 \mathrm{~h}$ per week), but this finding was based on a very small number of persons. When the job-exposure matrix was used, no increased risk for prolonged time to pregnancy was found. Use of the job-exposure matrix may have introduced a nondifferential misclassification of exposure, which would have led to a bias towards the null $(18,19)$. However, the exposure matrix was based on information from noncases and reflects true exposure. Therefore, nondifferential misclassification cannot explain the finding of no effects at all $(18,19)$. Recall bias thus remains a possible explanation. In particular, recall bias might be expected among those waiting $\geq 13$ months to conceive. Therefore, bearing the shortcomings of the study in mind, one should interpret the results with caution.

\section{Acknowledgments}

We thank Dr J Olsen, Dr NJ Secher, Dr KO Larsen, and Ms L Helsborg for their scientific assistance; Ms B Waldstroem, Ms AC Dam, Ms LT Nielsen, and Ms AT Johansen for their technical and administrative support; Ms H Brandt, Ms H Bräuner, Ms K Johansen, and Ms $\mathrm{H}$ Nicolaisen for performing the telephone interviews; and finally The Union of Commercial and Clerical Employess in Denmark for participating in the study.

The study was financed by the Occupational Medical Research Fund in Aarhus, the Medical Research Fund, and the Health Fund.

\section{References}

1. Brandt LPA, Nielsen CV. Congenital malformations among children of women working with video display terminals. Scand J Work Environ Health 1990;16:32933.
2. Nielsen CV, Brandt LPA. Spontaneous abortion among women using video display terminals. Scand J Work Environ Health 1990;16:323-28.

3. Ericson A, Källen B. An epidemiological study of work with video screens and pregnancy outcome: II. a casecontrol study. Am J Ind Med 1986;9:459-75.

4. Goldhaber MK, Polen MR, Hiatt RA. The risk of miscarriage and birth defects among women who use visual display terminals during pregnancy. Am J Ind Med 1988;13;695-706.

5. Kurppa K, Holmberg PC, Rantala K, Nurminen T, Saxén $\mathrm{L}$. Birth defects and exposure to video display terminals during pregnancy: a Finnish case-referent study. Scand J Work Environ Health 1985;11:353-6.

6. McDonald AD, Cherry NM, Delorme C, McDonald JC. Visual display units and pregnancy: evidence from the Montreal survey. J Occup Med 1986;28:1226-31.

7. Bryant HE, Love EJ. Video display terminal use and spontaneous abortion risk. Int J Epidemiol 1989;18: $132-8$.

8. Schnorr TM, Grajewski BA, Hornung RW, Thun MJ, Egeland G, Murray WE, et al. Video display terminals and the risk of spontaneous abortion. $\mathrm{N}$ Engl J Med 1991;324:727-33.

9. Windham GC, Fenster L, Swan SH, Neutra RR. Use of video display terminals during pregnancy and the risk of spontaneous abortion, low birth weight, or intrauterine growth retardation. Am J Ind Med 1990;18: $675-88$.

10. Tikkanen J, Heinonen OP, Kurppa K, Rantala K. Cardiovascular malformations and maternal exposure to video display terminals during pregnancy. Eur $\mathbf{J}$ Epidemiol 1986;6:61-6.

11. Baird DD, Wilcox AJ, Weinberg CR. Use of time to pregnancy to study environmental exposures. Am J Epidemiol 1986;124:470-80.

12. Dean J, Dean A, Burton A, Dicker R. Epi info version 5.00 [computer program]. Geneva: World Health Organization, 1990.

13. Kleinbaum DG, Kupper LL, Morgenstern H. Epidemiologic research; principles and quantitative methods. New York, NY: Lifetime Learning Publications, 1982: chapter 11 .

14. Schaumburg I, Olsen J. Time to pregnancy among Danish pharmacy assistants. Scand J Work Environ Health 1989;15:222-6.

15. Baird DD, Wilcox AJ. Cigarette smoking associated with delayed conception. JAMA 1985;253:2979-83.

16. Olsen J, Rachootin P, Schiødt AV, Damsbo N. Tobacco use, alcohol consumption and infertility. Int $\mathrm{J}$ Epidemiol 1983;12:179-84.

17. Olsen J. Subfecundity according to the age of the mother and the father. Dan Med Bull 1990;37:281-2.

18. Axelson $\mathrm{O}$. A note on observational bias in case-referent studies in occupational health epidemiology [letter]. Scand J Work Environ Health 1980;6:80-2.

19. Olsen J. Limitation in the use of job exposure matrix. Scand J Soc Med 1988;16:205-8.

Received for publication: 20 December 1991 